\title{
Non-motor signs in Parkinson's disease: a review
}

\author{
Sinais não motores na doença de Parkinson: uma revisão \\ Renato P. Munhoz', Adriana Moro ${ }^{2,3}$, Laura Silveira-Moriyama ${ }^{4}$, Helio A. Teive²
}

\begin{abstract}
During the past decade the view of Parkinson's disease (PD) as a motor disorder has changed significantly and currently it is recognized as a multisystem process with diverse non-motor signs (NMS). In addition to been extremely common, these NMS play a major role in undermining functionality and quality of life. On the other hand, NMS are under recognized by physicians and neglected by patients. Here, we review the most common NMS in PD, including cognitive, psychiatric, sleep, metabolic, and sensory disturbances, discuss the current knowledge from biological, epidemiological, clinical, and prognostic standpoints, highlighting the need for early recognition and management.
\end{abstract}

Keywords: Parkinson's disease, non-motor signs, dementia, hyposmia, psychosis.

\section{RESUMO}

No decorrer da última década, a visão da doença de Parkinson (DP) como um distúrbio de movimento puro mudou significativamente, sendo atualmente reconhecida como um processo multisistêmico com diversos sinais não motores (SNM). Além de serem extremamente comuns, estes SNM têm um impacto muito significativo na limitacão funcional e da qualidade de vida na DP. Por outro lado, os SNM são mal reconhecidos pelos clínicos e negligenciados pelos pacientes. Nessa revisão os SNM mais comuns na DP foram detalhados, incluindo distúrbios cognitivos, psiquiátricos, do sono, metabólicos, e sensitivos; e discutindo o conhecimento atual sob o ponto de vista biológico, epidemiólogico, clínico e prognóstico, destacando a necessidade de reconhecimento e abordagem terapêutica precoces.

Palavras-chave: doença de Parkinson, sinais não-motores, demência, hiposmia, psicose.

The traditional pathological description of PD as a pre-synaptic degenerative process affecting dopaminergic neurons in the substantia nigra pars compacta (SNc) of the midbrain with formation of Lewy bodies (LB) has changed dramatically in the last decade since functional and neuropathological studies showed the occurrence of extensive extranigral involvement ${ }^{1}$. Among these investigations, the seminal study of Braak et al. ${ }^{2}$ suggested that the degenerative process in the PD starts in the caudal regions of the brainstem and the olfactory bulb, progressing in the caudal-rostral direction. The involvement of the SNc occurs, according to this hypothesis, on the third of a six-stage process that begins in the dorsal motor nuclei of the glossopharyngeal and vagus nerves and the olfactory bulb. Although it demonstrates the occurrence of this peculiar pathological distribution, the study fails to make the clinical correlation between any of these changes and motor or non-motor manifestations. On the other hand, even considering this caveat, it was one of the studies that formed the basis and motivated the dissemination of the concept of the existence of non-motor signs (NMS), especially dysautonomia, olfaction and sleep disorders, as part of the disease, sometimes even preceding the classic motor symptoms of PD.

The motor aspects of PD typically have a slow progression and direct correlation with the presence of neuronal degeneration in the SNc, but they do not represent the actual beginning of the degenerative process. This process is, in fact, in full progression, despite been apparently silent when one seeks only for motor signs ${ }^{3}$.

\section{EXTRANIGRAL DEGENERATION}

The notion of PD as a multisystemic disease, not restricted to the nigrostriatal tract is not new, however the cited

\footnotetext{
'University of Toronto, Toronto Western Hospital, Movement Disorders Centre, Toronto ON, Canada;

¿2Universidade Federal do Paraná, Hospital de Clínicas, Unidade de Distúrbios do Movimento, Curitiba PR, Brazil;

${ }^{3}$ Associação Paranaense dos Portadores de Parkinsonismo, Curitiba PR, Brazil;

${ }^{4}$ Universidade Nove de Julho, Sao Paulo SP, Brazil.

Correspondence: Renato P Munhoz; 399 Bathurst Street; ML-7 Toronto, ON, Canada M5T 2S8; E-mail: renato.munhoz@uhn.ca

Conflict of interest: There is no conflict of interest to declare.

Received 20 January 2015; Accepted 09 February 2015.
} 
study of Braak et al. ${ }^{2}$ not only showed that the degenerative process begins in non-dopaminergic structures of the brain stem, or even in the peripheral autonomic system, but also influenced the way in which we interpret apparently nonspecific signs that can be detected in the course of the disease. Another innovative aspect of this hypothesis is that the disease process advances in a sequential and predictable manner. Thus, when the process affects the SNc, components of other brainstem structures are already heavily affected. Also, from the moment when the motor signs appear, other brainstem nuclei will also degenerate, until finally the degenerative process reaches the anteromedial temporal cortex and then the neo cortex, starting with associative and pre frontal, until finally sensory, motor and pre motor areas are affected.

This concept, however, does not escape criticism and between $6 \%$ and $43 \%$ of the cases described in other pathological studies published since then do not fit perfectly with this model, especially the sequential aspect ${ }^{4}$. For example, a study that evaluated pathologically confirmed cases of PD with the intention of testing the Braak's model, showed that the distribution of the pathological markers is consistent with this pattern, but also showed that the pathologic density in the brainstem was different from the cortex, indicating that the accumulation of degeneration occurs in these two regions independently. Another important point was the lack of an adequate correlation between the clinical and pathological findings in terms of duration and severity of motor and NMS and between neuronal loss density and these same clinical variables 5 . Finally, almost $10 \%$ of cases from other pathological series feature the degenerative process markers in the midbrain and cortex, but not in the most caudal areas of the brainstem, contrary to the model of an upward progression from the medulla.

Regardless of the lack of consonance of pathological studies in PD, especially in terms of its dynamic distribution during the course of the disease, the literature is unanimous in regards to its progressive and diffuse distribution, advancing in either phase of the disease to cortical and subcortical areas, not restricted to the motor system.

\section{PREVALENCE AND IMPACT OF NON-MOTOR SIGNS OF PARKINSON'S DISEASE}

Most, if not all, patients with PD present NMS. A survey that included 1,072 patients with PD using a structured questionnaire conducted in Italy showed that $98.6 \%$ of patients had at least one of the SNM studied, including more commonly psychiatric, sensory and sleep-related symptoms. On average, in this study, each patient had about eight symptoms, a figure that increased according to the duration of the disease and its severity ${ }^{6}$. These NMS can occur at any time in the course of the disease, however some are generally described in the early stages, such as REM sleep behavior disorder (RBD), olfactory disorders and constipation. Others tend to occur in the later stages, such as psychosis and cognitive deficits. A third group of these symptoms do not have a clear relationship with stages of the disease, including depression and forms of dysautonomia?

The functional and the quality of life (QoL) related impact of NMS is very significant, equaling or even surpassing those imposed by common motor symptoms of PD. A comprehensive review of the literature assessing the main determinants of QoL in PD showed that this parameter tends to deteriorate in the later stages; however it does not correlate closely with disease duration and clinical assessment scores. On the other hand, the presence and severity of symptoms of depression, cognitive impairment and sleep problems have a strong correlation with QoL scores. This review also showed that in half of the studies, the main limitation of QoL was a NMS, similar to the motor signs classically considered refractory and disabling such as postural instability and gait disorders ${ }^{8}$. From a different perspective, a study that evaluated the main limiting factors of activities of daily living (ADL) in patients undergoing stereotactic surgery with deep brain stimulation for the treatment of PD, showed that after nine years since the intervention, non-axial signs, including tremor, rigidity and bradykinesia, remained relatively stable. However, axial signs (postural instability and gait disorder) and NMS began to exert a growing negative effect, reflecting levels of functionality that were similar or worse than those observed before surgery9.

NMS represent some of the leading causes of disability and impairment in QoL in PD, therefore, the recognition of these aspects of the disease is essential to provide care that can potentially induce a decisive and comprehensive impact in these cases ${ }^{10}$. Despite its importance and frequency, NMS are not adequately recognized in clinical practice. The impact and the ability to detect NMS in specialized consultations were the focus of the study by Gallagher et al. ${ }^{11}$ that evaluated cases divided into those with advanced disease and another group with a confirmed diagnosis of PD for less than least five years, which was considered "recent diagnosis". In both situations the NMS were common and associated with limitations in QoL that surpassed those caused by motor dysfunction. Interestingly, the NMS with the greatest impact were the same in both groups: autonomic dysfunction and fatigue, added by depression for the group with more recent diagnosis. The ability to detect NMS is not uniform. In part this is due to the perception that certain NMS are not directly related to the DP, such as apathy and sphincter dysfunctions, so patients do not spontaneously report and the complaints can be missed during routine clinical investigations. Depression and hallucinations appear to be routinely investigated in some studies but not in others ${ }^{11}$. Most studies evaluating the ability to detect NMS compare the clinical documentation of consultations with results of specific questionnaires that were not designed and validated instruments to be used by the clinician on a daily basis. Thus, other 
explanations for these differences are the presence of falsepositive responses to the questionnaires, lack of hope for the resolution of problems in spite of motor symptoms that are considered "legitimate" neurological, and insufficient time for consultation.

Another study analyzed the results of a series of scales and NMS-related questionnaires compared to the chance of identifying these same signs by the neurologist who treated the patient with PD. This study showed that depression, anxiety, fatigue, and sleep disturbances are not identified in almost $50 \%$ of visits ${ }^{12}$. A study with similar methodology assessed which were the NMS observed in PD patients among the ones listed in a specific questionnaire compared to those cited by the same patients during a specialized routine medical consultation. Almost $43 \%$ of NMS noted in the questionnaire had not been mentioned in the consultation, including hallucinations, sleep disorders (insomnia and RBD), drooling and restless legs syndrome. The authors highlight that from the list of non-declared NMS, most were potentially treatable. This study also found more NMS among patients with the rigid akinetic form of $\mathrm{PD}^{13}$. A study involving cases with pathological confirmation of PD retrospectively seeking the first signs of the disease, showed that nearly a quarter of the patients had NMS in the early stages and that the presence of such symptoms led to a greater chance of demand for orthopedic surgeons and rheumatologists than neurologists ${ }^{14}$.

\section{CLINICAL CHARACTERIZATION OF NON-MOTOR SIGNS IN PARKINSON'S DISEASE}

We discuss below a few key points about each individual NMS. Autonomic dysfunction also comprehends an important and broad group of NMS that is not included in this review (except for constipation) due to length restrictions and also because we believe this particular topic deserves a review on its own.

A summary of prevalence, its correlation with disease progression, level of functional disability and potential role as premotor signs of PD is presented in Table 1 and Figure.

\section{Olfactory deficit}

The first description of olfactory deficits in PD was made almost 40 years ago ${ }^{15}$ and five years later this signal was described as an early feature and a "precursor of motor signs" 16 . During the 80s, studies have shown that discrimination, detection threshold, and identification of odors are abnormal in $\mathrm{PD}^{17,18}$. In addition, sequential studies have shown that olfactory deficits in these cases do not depend on odor subtype, age of onset, duration and severity of the disease, motor laterality and phenotype, treatment, and presence of cognitive impairment ${ }^{19,20}$. Finally, a more recent study showed that hyposmia does not fluctuate during periods on and off ${ }^{21}$. The
Table 1. Non-motor signs: prevalence, respective level of functional disability and potential role as premotor signs of Parkinson's disease $15,16,17,18,19,35,43,44,45,47,48,49,51,52,53,60$

\begin{tabular}{lccc}
\hline & Prevalence* (\%) & Disability & PMS \\
\hline Hyposmia & $50-75$ & + & + \\
RBD & $42-58$ & ++ & + \\
Depression & $35-68$ & ++++ & $-\star *$ \\
Constipation & $50-79$ & ++ & + \\
Weight loss*** & $21-30$ & + & + \\
Dementia & $48-78$ & ++++ & - \\
Psychosis & $50-80$ & +++ & - \\
\hline
\end{tabular}

PMS: Pre motor sign; RBD: REM sleep behavior disorder. * Life time prevalence; **Probably a pre morbid risk factor, not a PMS; $\star * \star$ Mild/moderate weight loss has been documented as a PMS.

Prevalence figures represent undernutrition.

combination of these data indicates that this dysfunction is not directly related to the dopaminergic dysfunction or with the degenerative process responsible for motor signals of PD. In fact, a study that evaluated cholinergic and dopaminergic innervation concluded that the cholinergic deficit, especially located in the limbic cortex, represents a more robust determinant to olfactory deficits in PD than nigrostriatal dopaminergic denervation ${ }^{22}$.

From a pathophysiological point of view, the presence of LB in the olfactory bulb seems to be a constant finding in patients with symptomatic PD, occurring in $100 \%$ of cases examined post-mortem. Congruent with the hypothesis described by Braak et al. ${ }^{2}$ cited previously, which proposes that the degenerative process in $\mathrm{PD}$ also begins in the olfactory bulb and anterior olfactory nuclei, loss of olfactory sensitivity occurs in 70\%-90\% of patients with PD, including newly diagnosed cases who did not yet receive any form of treatment ${ }^{23}$. Besides being an inherent part of the established disease, several evidences suggested and consolidated the hypothesis that hyposmia is an early sign of pre-motor DP, starting with the fact that the presence of LB in the SNc invariably accompanied these pathological markers in the olfactory structures. The opposite, however, is not always true, i.e., many cases have LB in the olfactory bulb with intact SNc. The length of time between the expression of hyposmia and the appearance of motor signs is still unknown and may be of several years ${ }^{24}$.

Since the early 1990s, it was demonstrated that olfactory deficits could distinguish sporadic PD from essential tremor, dystonic tremor and progressive supranuclear palsy (PSP) ${ }^{25}$. Later, this same conclusion was determined with respect to multiple system atrophy (MSA), cortico basal degeneration and monogenic parkinsonism related to mutations in the PINK1 and PARK2 genes ${ }^{26,27}$ while cases with mutations in the LRRK2 gene have intermediate results ${ }^{28,29}$.

The main longitudinal study showing that the olfactory deficit may precede PD was held in Honolulu, Hawaii, by the group of Ross et al. ${ }^{30}$ who published a series of articles showing that in the longitudinal follow-up of more than 2,000 neurologically 


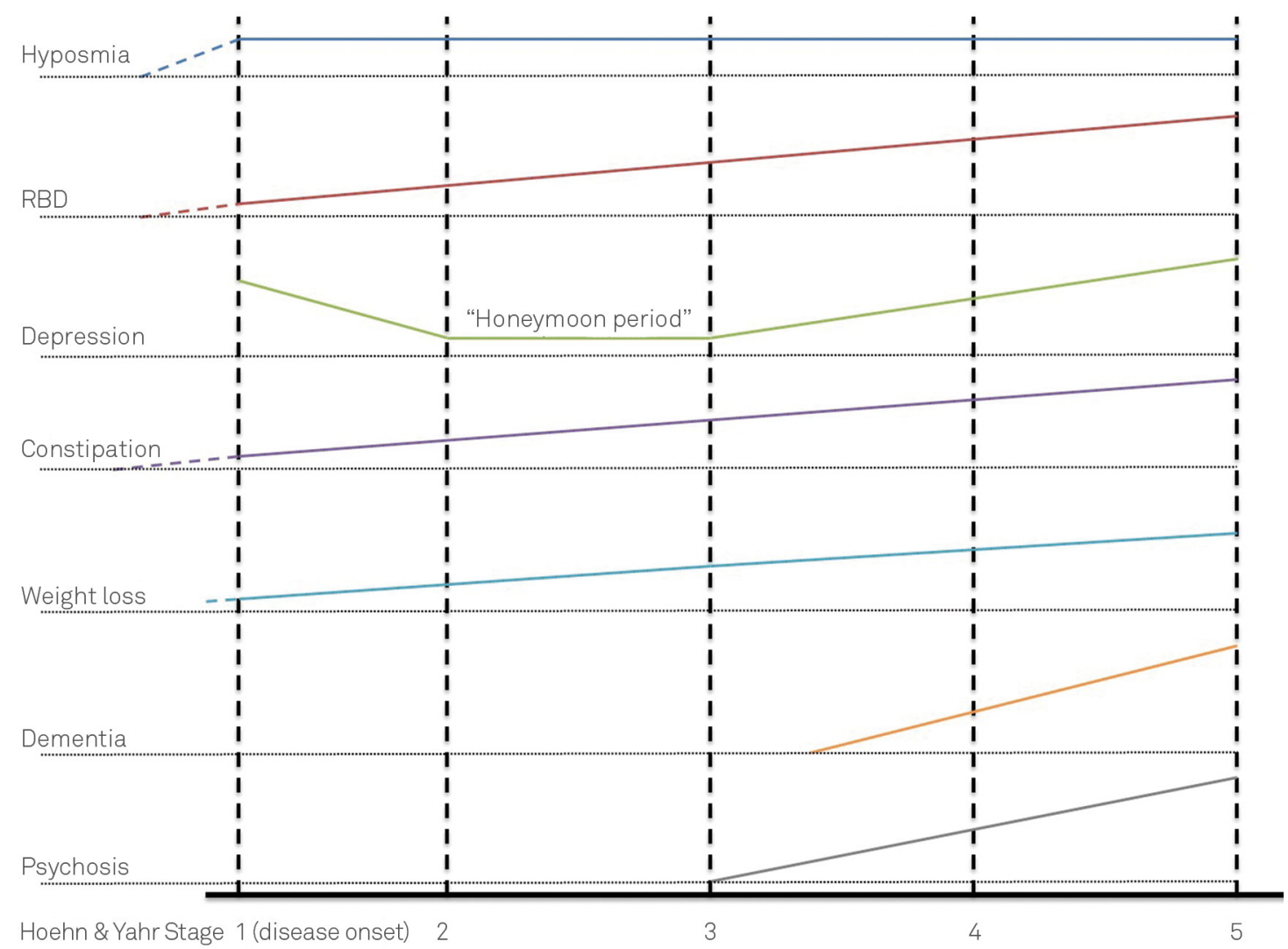

Figure. Progression of non-motor symptoms throughout disease stages in Parkinson's disease.

healthy elderly individuals, those with proven olfactory deficit had a higher risk of developing symptomatic PD clinical and when they remained asymptomatic, these individuals presented LB in the SNc on post- mortem examination. Other studies that strengthen the idea that the olfactory disorder precedes the motor onset of PD include those by include Berendse et al. ${ }^{31}$, and its follow-up after three years ${ }^{32}$ showing the development of PD signals in cases of a group of "high risk", which included family members of patients with PD who had hyposmia, while family members without hyposmia remained asymptomatic after two years. Finally, a study that evaluated possible associations between olfactory deficit and the risk of developing dementia in PD with an observation period of three years using functional imaging techniques showed that changes in the areas associated with olfactory function have a close relationship with cognitive decline. In addition, the study also showed that more severe hyposmia represents a prominent factor for the development of dementia ${ }^{33}$.

\section{REM sleep behavior disorder}

Physiologically, patterned changes of neuronal activation and release of specific neurotransmitters in the brain stem occur during the REM sleep phase, inducing, among other phenomena, motor inhibition and muscle atonia. RBD is a parasomnia characterized by the loss of this normal muscle atonia during this sleep stage ${ }^{34}$.
The gold standard for diagnosis requires polysomnography demonstrating excessive muscle activity, continued or intermittent tone of submentonian during REM sleep ${ }^{35}$. Clinically, the diagnosis can also be established using historical data using instruments that range from formal criteria of the Manual of Disorders of Sleep of the American Academy of Sleep Medicine ${ }^{36}$ to the use of a single question with a categorical "yes or no" type answer ${ }^{37}$. The typical clinical picture includes a description of movements associated with dream content and aggressive behavior with interpretation of such contents. Since the dream content in these cases tends to involve conflict situations, there is usually sleep disruption of patients and/or their bed partner, who are occasionally victims to physical harm, including descriptions of trauma with significant severity ${ }^{35}$. Patients with PD and RBD probably have a different distribution of the degenerative process compared to those without this parasomnia, once it's the most probable substrate involves the pons tegmentum and the medial nuclei of the medul$\mathrm{la}^{38}$. Clinically, RBD may be linked to particular manifestations such as worse scores of postural instability and gait, lower amplitude of motor response to levodopa, higher frequency of orthostatic hypotension and visual color perception deficit. From a behavioral point of view, RBD is associated with vivid dreams and visual hallucinations, and is a warning sign for the occurrence of dementia and other 
cognitive deficits involving specific episodic verbal memory, executive functions and visuospatial and visuoperceptual processing ${ }^{35}$.

Interestingly, a study that analyzed the quality of the movements during episodes of RBD showed that they do not have the standard asymmetric signs of parkinsonism observed during wakefulness, and are rapid, large, coordinated and symmetrical, however violent, ballistic and occasionally repetitive, suggesting that during REM sleep there may be a transient re-establishment of more physiological basal ganglia function. Alternatively, parkinsonism may disappear during REM sleep because at this stage the movements generated follow directly to pyramidal tract neurons and sequentially to the peripheral motor neuron, bypassing the extrapyramidal system and the physiological barrier responsible for atonia during this sleep stage in the brainstem ${ }^{39}$.

RBD occurs in up to half of PD patients and, as in the case of hyposmia, is considered an established pre-motor symptom. Also, in almost half of PD patients and RBD, the sleep complication precedes the onset of parkinsonism by several years. The mean interval from the onset of symptoms of $\mathrm{RBD}$ and motor signs is 11 to 12 years, but may range from 1 to up to $20^{35}$. Moreover, cases of apparently idiopathic RBD are uncommon and have a chance of more than $50 \%$ to develop neurodegenerative diseases after 12 years of follow up, including more commonly $\mathrm{PD}$, followed by LB dementia, Alzheimer's disease and $\mathrm{MSA}^{40}$. Another important aspect is that individuals with idiopathic RBD with the highest chance of developing PD have peculiar sleep characteristics, including higher proportion of REM sleep, more periodic lower limb movements per hour during of non-REM sleep and abnormal intensity of muscle atonia ${ }^{41}$. Finally, although RBD is described in atypical forms of parkinsonism associated with the pathological background of synucleinopathies, particularly multiple system atrophy and LB dementia, their occurrence in PSP, although less common, is significant, indicating the concept that this parasomnia is not related to a specific molecular form, but rather to a specific topographic progression of the degenerative process ${ }^{42}$.

\section{Behavioral disorders}

Mood disorders are common in PD, occurring in more than a quarter of newly diagnosed cases. Several studies have also shown that individuals with depression are 2.2 to 3.2 times more likely to develop PD compared to healthy controls ${ }^{43}$. Although the available data regarding this correlation are less conclusive than for hyposmia and RBD, the onset of depressive symptoms may precede the motor signs, with a peak around 3-6 years before the diagnosis of PD. One of these studies evaluated 1,358 patients with depression and 67,570 healthy individuals matched for age and sex for an average period of 15 years, showing a chance of occurrence of PD in those with a history of depression 13.3 times higher than controls without depression. Another epidemiological study found similar results with a chance of 2.95 times for the occurrence of PD in individuals with depression. In these studies and in the literature in general, depression is considered a risk factor, as well as family history and life in a rural environment, but not necessarily a pre-motor symptom ${ }^{44}$.

In the course of the disease, depression is one of the major indicators of a poor quality of life and functional disability, occurring in about $40 \%$ of patients in cross-sectional studies and almost $70 \%$ in longitudinal studies ${ }^{8}$. The diagnosis of depression in PD may be complex because some of the signs of the disease itself may mimic it. Moreover, there are peculiar aspects regarding the presence and severity of depressive symptoms compared to the general population with depression (Table 2) PD depression tends to manifest with more intense anxiety, pessimism, hopelessness, social withdrawal, self-depreciative thoughts, and introversion, but, on the other hand, less felling of guilt, ideation of death and suicide ${ }^{8}$.

Depression in PD is probably multifactorial, involving a neurobiological substrate permeated by evidence of a reactive component related to living with a chronic neurodegenerative disease and its complications and limitations. For example, a study by Rickards et al. ${ }^{45}$ showed that the frequency of depression is high in the early stages of PD, when the patient is diagnosed, decreasing when starting treatment, reflecting the classic "honeymoon phase", and increasing again with the progression of symptoms in later stages. In addition, depression in $\mathrm{PD}$ is directly related to the severity of motor symptoms and may fluctuate along with motor fluctuations, reflecting the pharmacological effect of levodopa. The biological basis of depression also has a pathological basis, related to the presence of PD's own degeneration markers in serotonergic and noradrenergic structures as the raphe nuclei and limbic structures ${ }^{8}$.

Still under the behavioral aspect, a premorbid personality in PD has been observed, including a relatively uniform description that often uses terms such as introversion,

Table 2. Clinical differentials in presentation of depression in Parkinson's disease (PD) versus the general population.

\begin{tabular}{l} 
More common in PD depression \\
\hline Apathy \\
Dysphoria \\
Irritability \\
Anxiety \\
Fluctuation of mood throughout the day \\
Pessimism \\
Hopelesness \\
Social withdrawal \\
Introversion \\
Self-deprecating thoughts \\
Uncommon in PD depression \\
Sensation of guilt \\
Self punishment \\
Death ideation \\
Suicide
\end{tabular}


behavioral inflexibility, difficulty with abstraction thought, more reliability, responsibility, loyalty, subordination, less tendency to leadership, conservative attitude with self-protection, intense self-control and difficulty expressing aggression. Unfortunately, these aspects are all very common in the general population and have a low specificity for $\mathrm{PD}^{46}$.

\section{Constipation}

The clinical history of constipation is common at diagnosis in cases of $\mathrm{PD}$, and is also described before the emergence of motor signs. As a pre-motor symptom, it was described in a variable period that can reach up to 24 years before the onset of parkinsonism in studies using different methodologies. In a longitudinal study of 6,790 males with constipation, the risk of occurrence of PD was 2.7 times higher than in those without this symptom. In this study, the mean time interval between the detection of constipation to diagnosis of PD was 12 years, ranging from two months to 24 years ${ }^{47}$.

The pathological support of this relationship comes from the observation that $9 \%$ to $17 \%$ of healthy subjects have alpha synuclein aggregates in the peripheral autonomic system, including abdominal-pelvic, cardiac and myenteric plexus of the esophagus, sympathetic ganglia and vagus nerve. Thus, from the pathophysiological point of view, constipation may reflect not only this peripheral involvement but also central mechanisms that cause pelvic floor dysfunction. Some of these individuals with peripheral autonomic disorder still present LB in the central nervous system and others have other pre-motor signs such as RBD, striatal abnormalities in functional tests or even pre-diagnostic PD as described above, in another words, the presence of a subtle cardinal sign that did not fill formal criteria for $\mathrm{PD}^{47,48}$.

\section{Weight loss}

Several studies have found that PD patients have lower body mass index (BMI), compared to healthy controls matched for sex and age. The etiology seems to be multifactorial, related to the presence of dyskinesias, change in eating habits, effect of medication (mainly levodopa), longer time for the ingestion of meals leading to lower energy intake and earlier satiety, in addition to being potentially related to intrinsic physiological changes of the neurodegenerative process. For example, the concentration of leptin, insulin-like growth factor type 1 (IGF-1), and thyroid-stimulating hormone were investigated in patients with $\mathrm{PD}$ and weight loss compared to controls with PD but no weight loss, finding lower levels of leptin and higher IGF-1 in the study group ${ }^{49,50}$.

The onset of weight loss in PD does not have a defined correlation with the stages of the disease, and may be an early expression or even precede the onset of motor signs. A prospective study that examined the changes in BMI in 468 patients with PD using anthropometric data collected before the onset of motor symptoms, followed during the course of the disease showed that the average body mass remained stable in most subjects up to a variable period before the onset of motor signs. This period ranged from a few months up to four years. Interestingly, this study showed a tendency to the increase in caloric intake while the BMI decreased. In the course of the disease, the reduction of BMI followed a continuous process with the same tendency of the pre-motor period, indicating that, regardless of the process that triggers this early change in BMI, it is relatively uniform and follows the disease progression ${ }^{51}$.

\section{Cognitive deficit}

Several degrees of cognitive impairment are common features of PD and, considering the model of disease progression described by Braak, may be a natural consequence of end-stage disease $e^{2}$. The diagnosis of dementia is also especially common in PD, It has been described in about $20 \%$ of PD cases in crosssectional studies ${ }^{52}$, and almost $80 \%$ in longitudinal studies, with an incidence at least four times greater than in the general population ${ }^{53}$. Furthermore, despite being more common and severe in the later stages, cognitive impairment that does not cause enough dysfunction to fulfill diagnostic criteria for dementia may be present early in the course of the disease, with abnormalities in neuropsychological tests detected in up to $24 \%$ of patients at diagnosis of PD. Finally, those with the formal diagnosis of dementia will present it for an average period of four years during the course of the disease ${ }^{53}$.

Cognitive disorders tend to exacerbate the motor symptoms disabilities in PD. In fact, the presence of cognitive impairment or dementia in PD patients is associated with loss of independence, poor quality of life and shortening of lifespan. Moreover, individuals in advanced stages of PD who develop dementia, often present a functional decline that follows a stereotyped pattern, indicating that the beginning of this sign announces the need for a more intensive care and increased risk of mortality ${ }^{54}$. Thus, the onset and progression of cognitive impairment in PD have an important influence on patient management and prognosis.

The phenomenology of specific cognitive symptoms associated with PD varies and probably reflects the heterogeneous underlying neuropathological substrate. The most common cognitive impairments are attention, executive behavior and visuospatial processing deficits, although patients may also exhibit different degrees of loss of memory, which could be, in some cases, a dysfunction secondary to a frontal (i.e., executive behavior) rescue information. In the same way, dementia in PD is not characterized by an intrinsic deficit of language, but may be associated with difficulty in processing and composition of phrases, which are also executive dysfunctions ${ }^{53}$. Some lines of research suggest that the executive impairments in PD are an early signal due to changes in dopaminergic stimulation in the frontal cortex, whereas impairments in semantic memory and visuospatial working correspond to the posterior neuropathological involvement of temporal and parietal cortex, conferring a higher risk of dementia in $\mathrm{PD}^{53}$. 
Among the risk factors for dementia in $\mathrm{PD}$, age is the most important. On the other hand, the increased age-related dementia risk does not seem to be associated with the possible influence of age of onset of motor symptoms; in other words, patients develop dementia in a similar mean age, regardless of when the motor signs appear ${ }^{54}$. Other studies also showed that cognitive impairment in PD correlates with the severity of motor disabilities, male gender, low education, visual hallucinations and the presence of rigidity and axial bradykinesia ${ }^{55}$.

The pathological basis for dementia in PD is, in part, related to the spread of LB to the cortex, which occurs in the later stages of disease ${ }^{2}$. Moreover, other studies show that the pathology of the cognitive impairment in PD is probably multifactorial, including LB and pathology characteristic of Alzheimer's disease, along with factors related to age and other comorbidities ${ }^{55}$.

The effect of treatment must also be considered, since pharmacological and non-pharmacological interventions could worsen incipient cognitive impairment. The use of anticholinergics, for example, classically enhances the cognitive symptoms of PD, as well as treatment with deep brain stimulation. In these cases, although the motor function has a good response to surgery, quality of life tends to decline after the first 6 months, probably, in part because of cognitive decline, which seems to be more significant when the target of this intervention is the subthalamic nucleus ${ }^{56}$.

\section{Psychosis}

Psychotic symptoms such as hallucinations and delusions are common in PD patients and occur from $10 \%$ to $80 \%$ of cases, depending on the definition and the studied population. Risk factors includes cognitive impairment, dementia, age greater than 65 years, advanced disease, longer duration, presence of sleep disorders, depression, visual disturbances and use of most of the drugs needed to treat motor symptoms of PD, the commonest culprits been dopamine agonists, levodopa, amantadine and anticholinergics ${ }^{57}$. Psychosis is associated with different pathological and molecular abnormalities, however the most consistent findings suggest the presence of LB in the temporal/limbic cortex ${ }^{58}$.

Diagnostic criteria include the presence of one of the following symptoms: illusions, false sense of presence, hallucinations and delusions in the context of previous diagnosis of PD defined by Queen Square Brain Bank criteria. In addition, symptoms should be recurrent or continuous for at least one month ${ }^{59}$ visual hallucinations tend to be more common, including a wide range of imagery, from simple indiscriminate shapes to well-formed entities with complex interaction with patients. Auditory hallucinations and other sensory functions are less common ${ }^{60}$.

As mentioned before, psychotic symptoms are more frequent in patients with cognitive impairment. In the case of a subclinical deficit, the presence of psychosis must be considered as a predictor of imminent cognitive decompensation and dementia. Thus, the so-called "benign" hallucinations are actually part of a gradual process with a potentially malignant prognosis ${ }^{60}$.

\section{FINAL REMARKS}

Despite the former cited observations about the functional and QoL related impact of NMS, until recently they received relatively little attention from clinicians. In part, that has happened due to unawareness and difficulties in conducting a more thorough and extensive assessment in a system that has limits of time and resources. Moreover, many patients and their caregivers tend to interpret NMS as being not "parkinsonian", not deserving evaluation by a specialist in neurological diseases. On the other hand, our review shows that most of the NMS that have a significant impact on QoL and functionality are, at least in part, manageable and should be properly and promptly identified.

\section{References}

1. Rajput $\mathrm{AH}$, Rozdilsky B, Rajput A. Accuracy of clinical diagnosis in parkinsonism: a prospective study. Can J Neurol Sci. 1991;18(3):275-8.

2. Braak H, Del Tredici K, Rüb U, Vos RA, Steur ENJ, Braak E. Staging of brain pathology related to sporadic Parkinson's disease. Neurobiol Aging. 2003;24(2):197-211.

3. Jellinger KA. A critical evaluation of current staging of alphasynuclein pathology in Lewy body disorders. Biochim Biophys Acta. 2009;1792:730-40. http://dx.doi.org/10.1016/S0197-4580(02)00065-9

4. Burke RE, Dauer WT, Vonsattel JP. A critical evaluation of the Braak staging scheme for Parkinson's disease. Ann Neurol. 2008;64(5):485-91. http://dx.doi.org/10.1002/ana.21541

5. Kingsbury AE, Bandopadhyay R, Silveira-Moriyama L, Ayling $\mathrm{H}$, Kallis C, Sterlacci W et al. Brain stem pathology in Parkinson's disease: an evaluation of the Braak staging model. Mov Disord. 2010;25(15):2508-15. http://dx.doi.org/10.1002/mds.23305
6. Barone P, Antonini A, Colosimo C, Marconi R, Morgante L, Avarello TP et al. The PRIAMO study: a multicenter assessment of nonmotor symptoms and their impact on quality of life in Parkinson's disease. Mov Disord. 2009;249(11):1641-9. http://dx.doi.org/10.1002/mds.22643

7. Chaudhuri KR, Odin P, Antonini A, Martinez-Martin P. Parkinson's disease: the non-motor issues. Parkinsonism Relat Disord. 2011;17(10):717-23. http://dx.doi.org/10.1016/j.parkreldis.2011.02.018

8. Schrag A. Quality of life and depression in Parkinson's disease.J Neurol Sci. 2006;248(1-2):151-7. http://dx.doi.org/10.1016/j.jns.2006.05.030

9. Zibetti M, Merola A, Rizzi L, Ricchi V, Angrisano S, Azzaro C et al. Beyond nine years of continuous subthalamic nucleus deep brain stimulation in Parkinson's disease. Mov Disord. 2011;26(13):2327-34. http://dx.doi.org/10.1002/mds.23903 
10. Chaudhuri KR, Healy D, Schapira AHV. Non-motor symptoms of Parkinson's disease: diagnosis and management. Lancet Neurol. 2006;5(3):235-45. http://dx.doi.org/10.1016/S1474-4422(06)70373-8

11. Gallagher DA, Lees AJ, Schrag A. What are the most important nonmotor symptoms in patients with Parkinson's disease and are we missing them? Mov Disord. 2010;25(15):2493-500. http://dx.doi.org/10.1002/mds.23394

12. Shulman LM, Taback RL, Rabinstein AA, Weiner WJ. Nonrecognition of depression and other non-motor symptoms in Parkinson's disease. Parkinsonism Relat Disord. 2002;8(3):193-7. http://dx.doi.org/10.1016/S1353-8020(01)00015-3

13. Chaudhuri KR, Prieto-Jurcynska C, Naidu Y, Mitra T, Frades-Payo $\mathrm{B}$, Tluk $S$ et al. The nondeclaration of nonmotor symptoms of Parkinson's disease to health care professionals: an international study using the nonmotor symptoms questionnaire. Mov Disord. 2010;25(6):704-9. http://dx.doi.org/10.1002/mds.22868

14. O'Sullivan SS, Williams DR, Gallagher DA, Massey LA, Silveira-Moriyama L, Lees AJ. Non motor symptoms as presenting complaints in Parkinson's disease: a clinicopathological study. Mov Disord. 2008;23(1):101-6. http://dx.doi.org/10.1002/mds.21813

15. Ansari KA, Johnson A. Olfactory function in patients with Parkinson's disease. J Chronic Dis. 1975;28(9):493-7. http://dx.doi.org/10.1016/0021-9681(75)90058-2

16. Korten JJ, Meulstee J. Olfactory disturbances in Parkinsonism. Clin Neurol Neurosurg. 1980;82(2):113-8. http://dx.doi.org/10.1016/0303-8467(80)90005-0

17. Ward CD, Hess WA, Calne DB. Olfactory impairment in Parkinson's disease. Neurology. 1983;33(7):943-6. http://dx.doi.org/10.1212/WNL.33.7.943

18. Quinn NP, Rossor MN, Marsden CD. Olfactory threshold in Parkinson's disease. J Neurol Neurosurg Psychiatry. 1987;50(1):88-9.

19. Doty RL, Deems DA, Stellar S. Olfactory dysfunction in parkinsonism: a general deficit unrelated to neurologic signs, disease stage, or disease duration. Neurology. 1988;38(8):1237-44.

20. Doty RL, Stern MB, Pfeiffer C, Gollomp SM, Hurtig HI. Bilateral olfactory dysfunction in early stage treated and untreated idiopathic Parkinson's disease. J Neurol Neurosurg Psychiatry. 1992;55(2):138-42. http://dx.doi.org/10.1136/jnnp.55.2.138

21. Saifee T, Lees AJ, Silveira-Moriyama L. Olfactory function in Parkinson's disease in ON versus OFF states. J Neurol Neurosurg Psychiatry. 2010;81(11):1293-95. http://dx.doi.org/10.1136/jnnp.2009.182022

22. Bohnen NI, Muller ML, Kotagal V, et al. Olfactory dysfunction, central cholinergic integrity and cognitive impairment in Parkinson's disease. Brain. 2010;133(6):1747-54. http://dx.doi.org/10.1093/brain/awq079

23. Hoyles K, Sharma JC. Olfactory loss as a supporting feature in the diagnosis of Parkinson's disease: a pragmatic approach. J Neurol. 2013;260(12):2951-8. http://dx.doi.org/10.1007/s00415-013-6848-8

24. Noyce AJ, Bestwock JP, Silveira-Moriyama L, Hawkes CH, Giovannoni G, Lees AJ et al. Meta-analysis of early nonmotor features and risk factors for Parkinson disease. Ann Neurol. 2012;72(6):893-901. http://dx.doi.org/10.1002/ana.23687

25. Busenbark KL, Huber SJ, Greer G, Pahwa R, Koller WC. Olfactory function in essential tremor. Neurology. 1992;42(8):1631-2.

26. Kertelge L, Bruggemann N, Schmidt A, Tadic V. Wisse C, Dankert S et al. Impaired sense of smell and color discrimination in monogenic and idiopathic Parkinson's disease. Mov Disord. 2010;25(15):2665-9. http://dx.doi.org/10.1002/mds.23272

27. Alcalay RN, Siderowf A, Ottman R et al. Olfaction in Parkin heterozygotes and compound heterozygotes: the CORE-PD study. Neurology. 2011;76(4):319-26. http://dx.doi.org/10.1212/WNL.0b013e31820882aa

28. Silveira-Moriyama L, Munhoz RP, Carvalho MJ, Raskin S, Rogaeva E, Aguiar PC et al. Olfactory heterogeneity in LRRK2 related Parkinsonism. Mov Disord. 2010;25:2879-83. http://dx.doi.org/10.1002/mds.23325
29. Marras C, Schule B, Munhoz RP, Rogaeva E, Langston JW, Kasten $M$ et al. Phenotype in parkinsonian and nonparkinsonian LRRK2 G2019S mutation carriers. Neurology. 2011;77(4):325-33. http://dx.doi.org/10.1212/WNL.0b013e318227042d

30. Ross GW, Petrovitch H, Abbott RD, Tanner CM, Popper J, Masaki $K$ et al. Association of olfactory dysfunction with risk for future Parkinson's disease. Ann Neurol. 2008;63(2):167-73. http://dx.doi.org/10.1002/ana.21291

31. Berendse HW, Booij J, Francot CM, Bergmans PL, Hijman R, Stoof JC et al. Subclinical dopaminergic dysfunction in asymptomatic Parkinson's disease patients' relatives with a decreased sense of smell. Ann Neurol. 2001;50(1):34-41. http://dx.doi.org/10.1002/ana.1049

32. Ponsen MM, Stoffers D, Booij J, Eck-Smit BL, Wolters ECH, Berendse HW. Idiopathic hyposmia as a preclinical sign of Parkinson's disease. Ann Neurol. 2004;56(2):173-81. http://dx.doi.org/10.1002/ana.20160

33. Baba T, Kikuchi A, Hirayama K, Nishio Y, Hosokai Y, Kanno S et al. Severe olfactory dysfunction is a prodromal symptom of dementia associated with Parkinson's disease: a 3 year longitudinal study. Brain. 2012;135(1):161-9. http://dx.doi.org/10.1093/brain/awr321

34. Schenk CH, Mahowald MW. REM sleep behavior disorder: clinical, developmental, and neuroscience perspectives 16 years after its formal identification in SLEEP. Sleep. 2002;25(2):120-38.

35. Postuma RB, Montplaisir J. Predicting Parkinson's disease: why, when, and how? Parkinsonism Relat Disord. 2009;15 Suppl 3:S105-9. http://dx.doi.org/10.1016/S1353-8020(09)70793-X

36. 36. American Academy of Sleep Medicine. ICSD - International classification of sleep disorders: diagnostic and coding manual. Westchester: American Sleep Disorders Association; 1990.

37. Postuma RB, Arnulf I, Hogl B, Iranzo A, Miyamoto T, Dauvilliers $Y$ et al. A single-question screen for rapid eye movement sleep behavior disorder: a multicenter validation study. Mov Disord 2012;27(7):913-6. http://dx.doi.org/10.1002/mds.25037

38. Postuma RB, Gagnon JF, Montplaisir J. Rapid eye movement sleep behavior disorder as a biomarker for neurodegeneration: the past 10 years. Sleep Med 2013;14(8):763-7. http://dx.doi.org/10.1016/j.sleep.2012.09.001

39. De Cock VC, Vidailhet M, Leu S, Teixeira A, Apartis E, Elbaz A et al. Restoration of normal motor control in Parkinson's disease during REM sleep. Brain. 2007;130(2):450-6. http://dx.doi.org/10.1093/brain/awl363

40. Munhoz RP, Teive HA, Eleftherohorinou H, Coin LJ, Lees AJ, Silveira-Moriyama L. Demographic and motor features associated with the occurrence of neuropsychiatric and sleep complications of Parkinson's disease. J Neurol Neurosurg Psychiatry. 2013;84(8):883-7. http://dx.doi.org/10.1136/jnnp-2012-304440

41. Vendette M, Gagnon JF, Décary A, Massicotte-Marquez J, Postuma RB, Doyon J et al. REM sleep behavior disorder predicts cognitive impairment in Parkinson disease without dementia. Neurology. 2007;69(19):1843-9. http://dx.doi.org/10.1212/01.wnl.0000278114.14096.74

42. Munhoz RP, Teive HA. REM sleep behaviour disorder: how useful is it for the differential diagnosis of parkinsonism? Clin Neurol Neurosurg. 2014;127:71-4. http://dx.doi.org/10.1016/j.clineuro.2014.09.014

43. Starkstein SE, Brockman S, Hayhow BD. Psychiatric syndromes in Parkinson's disease. Curr Opin Psychiatry. 2012;25(6):468-72. http://dx.doi.org/10.1097/YC0.0b013e3283577ed1

44. Leentjens AF, Van den Akker M, Metsemakers JF, Lousberg R, Verhey FR. Higher incidence of depression preceding the onset of Parkinson's disease: a register study. Mov Disord. 2003;18(4):414-8. http://dx.doi.org/10.1002/mds.10387

45. Rickards H. Depression in neurological disorders: Parkinson's disease, multiple sclerosis, and stroke.J Neurol Neurosurg Psychiatry. 2005;76 Suppl 1:i48-52. http://dx.doi.org/10.1136/jnnp.2004.060426

46. Ishihara L, Brayne C. What is the evidence for a premorbid parkinsonian personality: a systematic review. Mov Disord. 2006;21(8):1066-72. http://dx.doi.org/10.1002/mds.20980 
47. Abbott RD, Petrovitch H, White LR, Masaki KH, Tanner CM, Curb JD et al. Frequency of bowel movements and the future risk of Parkinson's disease. Neurology. 2001;57(3):456-62. http://dx.doi.org/10.1212/WNL.57.3.456

48. Cersosimo MG, Benarroch EE. Autonomic involvement in Parkinson's disease: pathology, pathophysiology, clinical features and possible peripheral biomarkers. J Neurol Sci. 2012;313(1-2):57-63. http://dx.doi.org/10.1016/j.jns.2011.09.030

49. Cheshire Jr WP, Wszolek ZK. Body mass index is reduced early in Parkinson's disease. Parkinsonism Relat Disord. 2005;11(1):35-8. http://dx.doi.org/10.1016/j.parkreldis.2004.07.001

50. Munhoz RP, Ribas CB. Body mass index in Parkinson's disease. Parkinsonism Relat Disord. 2005;11(6):407. http://dx.doi.org/10.1016/j.parkreldis.2005.02.001

51. Chen H, Zhang SM, Hernán MA, Willett WC, Ascherio A. Weight loss in Parkinson's disease. Ann Neurol. 2003;53(5):676-9. http://dx.doi.org/10.1002/ana.10577

52. Munhoz RP, Werneck LC, Teive HA. The differential diagnoses of parkinsonism: findings from a cohort of 1528 patients and a 10 years comparison in tertiary movement disorders clinics. Clin Neurol Neurosurg. 2010;112(5):431-5. http://dx.doi.org/10.1016/j.clineuro.2010.03.003

53. Aarsland D, Beyer MK, Kurz MW. Dementia in Parkinson's disease. Curr Opin Neurol. 2008;21(6):676-82. http://dx.doi.org/10.1097/WC0.0b013e3283168df0

54. Levy G, Schupf N, Tang MX, Cote LJ, Louis ED, Mejia H et al. Combined effect of age and severity on the risk of dementia in Parkinson's disease. Ann Neurol. 2002;51(6):722-9. http://dx.doi.org/10.1002/ana.10219

55. Buter TC, Hout A, Matthews FE, Larsen JP, Brayne C, Aarsland D. Dementia and survival in Parkinson disease: a 12-year population study. Neurology. 2008;70(13):1017-22. http://dx.doi.org/10.1212/01.wnl.0000306632.43729.24

56. Witt K, Daniels C, ReiffJ, Krack P, Volkmann J, Pinsker MO et al. Neuropsychological and psychiatric changes after deep brain stimulation for Parkinson's disease: a randomised, multicentre study. Lancet Neurol. 2008;7(7):605-14. http://dx.doi.org/10.1016/S1474-4422(08)70114-5

57. Munhoz RP, Espay AJ, Morgante F, Li JY, Teive HÁ, Dunn E et al. Long-duration Parkinson's disease: role of lateralization of motor features. Parkinsonism Relat Disord. 2013;19(1):77-80. http://dx.doi. org/10.1016/j.parkreldis.2012.07.008

58. Kalaitzakis ME, Christian LM, Moran LB, Graeber MB, Pearce RK, Gentleman SM. Dementia and visual hallucinations associated with limbic pathology in Parkinson's disease. Parkinsonism Relat Disord. 2009;15(3):196-204. http://dx.doi.org/10.1016/j.parkreldis.2008.05.007

59. Ravina B, Marder K, Fernandez HH, Friedman JH, McDonald W, Murphy D et al. Diagnostic criteria for psychosis in Parkinson's disease: report of an NINDS, NIMH work group. Mov Disord. 2007;22(8):1061-8. http://dx.doi.org/10.1002/mds.21382

60. Factor SA, Feustel PJ, Friedman JH, Comella CL, Goetz CF, Kurlan $\mathrm{R}$ et al. Longitudinal outcome of Parkinson's disease patients with psychosis. Neurology. 2003;60(11):1756-61. http://dx.doi.org/10.1212/01.WNL.0000068010.82167.CF 